\title{
EROSÃO REAL E ESTIMADA ATRAVÉS DA RUSLE EM ESTRADAS FLORESTAIS, EM RELEVO ONDULADO A FORTEMENTE ONDULADO ${ }^{1}$
}

\author{
Carla Maria Camargo Correa² e Jocelito Cruz ${ }^{3}$
}

\begin{abstract}
RESUMO - O objetivo deste trabalho foi avaliar as perdas de solo provenientes de trechos de estradas de uso florestal inseridas na região de Itaiópolis, Santa Catarina, que apresenta relevo ondulado a fortemente ondulado em dois tipos de solo: Cambissolo Húmico Distrófico típico e Argissolo Vermelho-Amarelo Distrófico típico. A erosividade da chuva foi calculada através de pluviogramas e de dados de pluviosidade da empresa Rigesa Soluções em Embalagens MeadWestvaco; a erosividade do solo foi calculada em função dos resultados de análises, a declividade e comprimento de rampa foram medidos em campo e os fatores $\mathrm{C}$ e $\mathrm{P}$, estipulados através da literatura. A hipótese de similaridade entre os valores reais monitorados pelo período de um ano e os valores estimados pela RUSLE foi evidenciada através de análise estatística, que apresentou alta correlação nos tratamentos avaliados e se manteve dentro do limite crítico proposto pela análise, validando, portanto, essa hipótese.
\end{abstract}

Palavras-chave: Perda de solo. Estradas florestais. Erodibilidade da chuva, declividade e comprimento de rampa.

\section{REAL AND ESTIMATIVE EROSION THROUGH RUSLE FROM FOREST ROADS IN UNDULATED AT HEAVILY UNDULATED RELIEF}

\begin{abstract}
The objective of this work was to evaluate the soil losses from a portion of forest roads located in a region with undulated to heavily undulated relief in two types of soil: Humic Cambissoil, typical Dystrophic and Red-Yellow Argissoil, typical Dystrophic. The rainfall erosivity was calculated using rainfall data through the Rigesa Company, the soil erodibility was calculated based on the results of the analyses, the declivity and the slope length were measured in the field, and Factors $C$ and $P$ were estimated from literature. The similarity hypothesis between the real values monitored over a one year period and the estimated values using the RUSLE were evidenced via statistical analyses that presented high correlations in the evaluated treatments, remaining inside the critical limit considered for the analyses, therefore validating the hypothesis.
\end{abstract}

Keywords: Soil losses. Forest roads. Rainfall erosivity, slope length and steepness.

\section{INTRODUÇÃO}

O desencadeamento de processos erosivos decorrentes da colheita e transporte de madeira é um dos principais problemas quando se trata de sustentabilidade ambiental em rede viária de uso florestal. Algumas particularidades desse tipo de transporte, como: tráfego pesado e extrapesado ocorrendo normalmente em um único sentido, por meio de veículos com capacidade de carga entre 30 e 40 toneladas, potencializam esses impactos ambientais, provocando deformações do leito carroçável e a ineficiência do sistema de drenagem (Camargo Correa et al., 2005; LOPES et al., 2002; GAYOSO e ALARCÓN, 1999).
Gayoso e Alarcón (1999) complementaram salientando que a degradação ambiental acontece durante a construção e manutenção de estradas, agravando-se durante a utilização, sobretudo em vias sem pavimentação e com qualidade técnica inferior, compreendendo estradas secundárias, terciárias, divisoras, contornos, ramais e aceiros. As características inerentes ao transporte e as atividades de colheita, associadas à utilização dessas estradas em períodos de chuva, transformam as estradas em canais escoadouros, facilitando o transporte de água e sedimentos, assoreando e poluindo mananciais (CAMARGO CORRÊA, 2005).

\footnotetext{
${ }^{1}$ Recebido em 23.11.2007 e aceito para publicação em 02.03.2010.

${ }^{2}$ Universidade Federal do Paraná, UFPR, Curitiba, Paraná, Brasil. E-mail: <camargocorrea@ufpr.br>.

${ }^{3}$ CNH - Companhia New Holland, Curitiba, Paraná, Brasil. E-mail: <jocelito.cruz@cnh.com>.
} 
O conhecimento e quantificação dos fatores que podem influenciar a erosão hídrica são de fundamental importância no planejamento de estradas. Nesse contexto, a Equação Universal de Perdas do Solo Revisada, também conhecida como Revised Universal Soil Loss Equation - RUSLE, é o modelo estatístico de predição de perda de solo amplamente utilizado em áreas agrícolas (BERTONI e LOMBARDI NETO, 1999; BORTOLOZZO e SANS, 2001), apresentando-se como instrumento capaz de estimar as perdas anuais de solo em estradas de uso florestal (CAMARGO CORRÊA, 2005). Alguns parâmetros que compõem a RUSLE também se encontram associados a outros modelos, como Water Erosion Prediction Project (WEPP) na quantificação de erosão em estradas (GARCIA et al., 2003; MACHADO et al., 2003), ou a sistemas de informação como Geographic Resources Analysis Support System (GRASS), utilizado para quantificar os sedimentos provenientes de estradas de uso florestal (ANTONANGELO, 2004).

Neste trabalho, avaliou-se a perda real de solo proveniente de trechos de estradas secundárias e de aceiros ou divisoras pelo período de um ano, e os resultados foram confrontados com as estimativas obtidas através da RUSLE, em que foram formuladas duas hipóteses:

- H alternativa $=$ as perdas de solo obtidas através da RUSLE possuem valores semelhantes aos das perdas reais de solo, apresentando-se dentro do limite crítico estabelecido pela seguinte relação ( $-\mathrm{tc}<\mathrm{t}<+\mathrm{tc}$ ).

- H nula = as perdas de solo obtidas através da RUSLE possuem valores diferentes estatisticamente aos das perdas reais de solo.

\section{MATERIAL E MÉTODOS}

\subsection{Descrição geral das áreas amostradas}

As Unidades de Manejo Florestal - UMFs são diferenciadas entre si em função das características de sítio, produtividade, manutenção, preservação e colheita. A rede viária de uso florestal nessas UMFs é submetida ao macroplanejamento, em que a densidade das estradas é ampliada e as condições técnicas são ajustadas para atender às necessidades das atividades de colheita e transporte de madeira.

Este trabalho foi desenvolvido em trechos de divisoras (aceiros) e estradas secundárias, em duas UMFs localizadas no Município de Itaiópolis, SC (UMFs
Ruthes e Leonel), que apresentam diferenciações nas condições de relevo e características edáficas. As estradas inseridas nessas UMFs não apresentam revestimento de leito e estão sob condição de relevo ondulado a fortemente ondulado. Os solos são de textura média argilosa a arenosa e, segundo Pinto (2005), representam cerca de 5\% das áreas de uso florestal da empresa.

O monitoramento dos trechos de estradas teve início em março de 2003 e término em junho de 2004. Durante esse período foram coletados, quinzenalmente, os sedimentos nas calhas e a água retida nos baldes, juntamente com as informações de precipitação provenientes de relatórios diários da empresa, como também de pluviógrafo instalado na UMF Ruthes, cujos dados de volume e intensidade de precipitação obtida pelo período de um ano, concentrando-se na época das chuvas, estão em conformidade com a metodologia também adotada por Machado et al. (2003), como se segue:

a) Clima: as regiões amostradas apresentam clima predominantemente do tipo Cfbl: temperado brando, chuvoso com verão fresco, segundo Köepen, com precipitação média anual de 1.800 mm, distribuídas com maior frequência nos meses de dezembro a maio e, em menor quantidade, nos meses de junho a outubro. A temperatura média anual foi de $18^{\circ} \mathrm{C}$, as médias mínimas alcançadas foram de $7^{\circ} \mathrm{C}$ e as médias das máximas, de $26^{\circ} \mathrm{C}$.

b) Estradas: foram avaliados trechos de estradas inseridas nas UMFs Ruthes e Leonel. O sistema viário nessas UMFs é composto por:

- Estradas com 32,37 km de extensão, com densidade de $24,31 \mathrm{~m} \mathrm{ha}^{-1}$.

- Divisoras ou aceiros internos com 23,72 km de extensão e densidade de 17,82 $\mathrm{m} \mathrm{ha}^{-1}$.

- Contorno ou aceiros externos com 23,69 km de extensão e densidade de $17,79 \mathrm{~m} \mathrm{ha}^{-1}$.

Algumas estradas principais apresentam o revestimento primário constituído de materiais sedimentares encontrados na região: folhelho, saibro ou cascalho; as secundárias e terciárias não apresentaram nenhum revestimento.

c) Geologia: segundo Mapa Geológico do Estado de Santa Catarina (1986), as UMFs apresentam a seguinte formação: Paleozoico/Permiano/médio e inferior. 
- Unidade litoestatigráfica: Subgrupo: Tubarão, Grupo: Guatá-Prb e Formação: Rio Bonito.

- Litologia e ambiente: Seção média: sedimentos marinhos compreendendo siltitos e folhelhos esverdeados com níveis carbonáticos argilosos silicificados em superfície e subordinadamente arenitos muito finos; Seção inferior: depósito flúvio-deltaítico, compreendendo arenitos imaturos arcossenos e subarcossenos, esbranquiçados, finos a médios, localmente grosseiros, argilosos micaceos e secundariamente arenitos muito finos, siltitos e argilitos, folhelhos carbonosos, leito de carvão e conglomerado.

d) Solos: as UMFs avaliadas apresentavam as seguintes classes de solos: argissolos, cambissolos e neossolos, estando os argissolos e neossolos restritos a algumas posições na paisagem. As áreas amostradas estão sobre as seguintes classes de solo.

- Cambissolo Húmico Distrófico típico, A húmico, álico, textura média, relevo ondulado. Nessa classe de solo foram instalados os tratamentos em trechos de estrada com conservação e a estrada do povoamento ou divisoras, com as respectivas áreas de contribuição. Essa classe de solo foi a de maior ocorrência na propriedade.

- Argissolo Vermelho-Amarelo Distrófico típico, A proeminente álico, textura argilosa, relevo ondulado. Este tipo de solo está localizado em situações de maior declividade, onde estão instalados os tratamentos no trecho de estrada sem conservação e respectiva área adjacente ou de contribuição.

As amostras de solo coletadas nessas UMFs apresentaram estrutura predominantemente granular com grau de desenvolvimento moderado ou forte, podendo ocorrer estrutura maciça e coesa devido à mecanização. A textura variou entre média e arenosa (350 a $80 \mathrm{~g} \mathrm{~kg}^{-1} \mathrm{de}$ argila), pertencente às classes francoarenoso, franco-argilo-arenoso ou argiloso com altos teores de silte.

e) Relevo: as condições de relevo encontradas nas áreas pertencem às classes: ondulado a fortemente ondulado, com interflúvios curtos e levemente aplanados; e encostas declivosas com pendentes longas; no entanto, as declividades horizontais máximas encontradas nos trechos de estradas avaliados nas UMF variaram de $12 \%$ a $15 \%$ e nas respectivas áreas de contribuição, de $12 \%$ a 16\%, no sentido do declive. Os trechos avaliados nas UMFs Ruthes e Leonel localizadas no Município de Itaiópolis estão apresentados na Figura 1.
Fonte: CAMARGO CORRÊA, 2005

Source: CAMARGO CORREA, 2005.

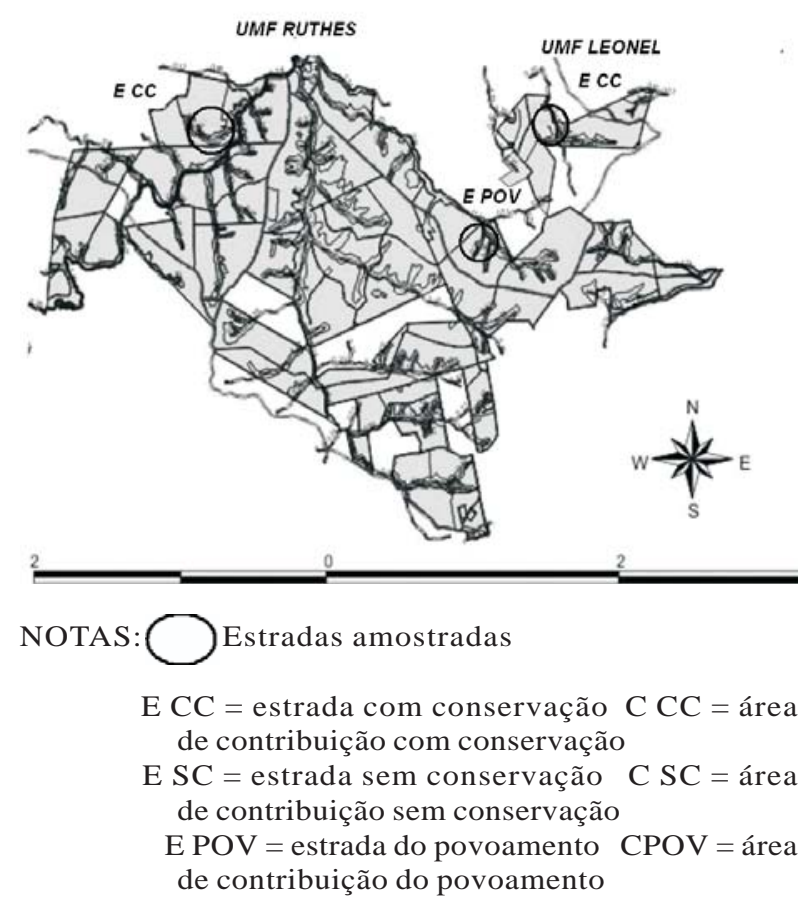

Figura 1 - Trechos de estradas avaliados nas unidades de manejo florestal localizada no Município de Itaiópolis.

Figure 1 - Parts of forest roads evaluated in FMUs located at Itaiópolis Municipal.

\subsection{Equipamentos e metodologia utilizada}

Para avaliação das perdas de solo e água, utilizou-se calha coletora de solo conhecida como amostrador de enxurrada tipo Coshocton (PARSONS, 1954), que determina o volume de solo e água perdidos através de escorrimento superficial. É constituído por uma roda com ranhuras na superfície e uma fenda (sampling head), que coletaram $1 \%$ do volume da enxurrada, sendo esse sedimento direcionado através de canos para baldes coletores com capacidade para $62 \mathrm{~L}$. Os detalhes dessa calha podem ser observados na Figura 2, onde foi instalada a calha na área de contribuição, adjacente ao tratamento de estrada com conservação.

Os sedimentos retidos nas calhas coletoras foram pesados quinzenalmente durante o período de monitoramento, sendo submetidos à análise de rotina,

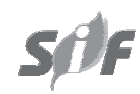

Revista Árvore, Viçosa-MG, v.34, n.4, p.587-595, 2010 
Fonte: CAMARGO CORRÊA, 2005.

Source: CAMARGO CORREA, 2005.

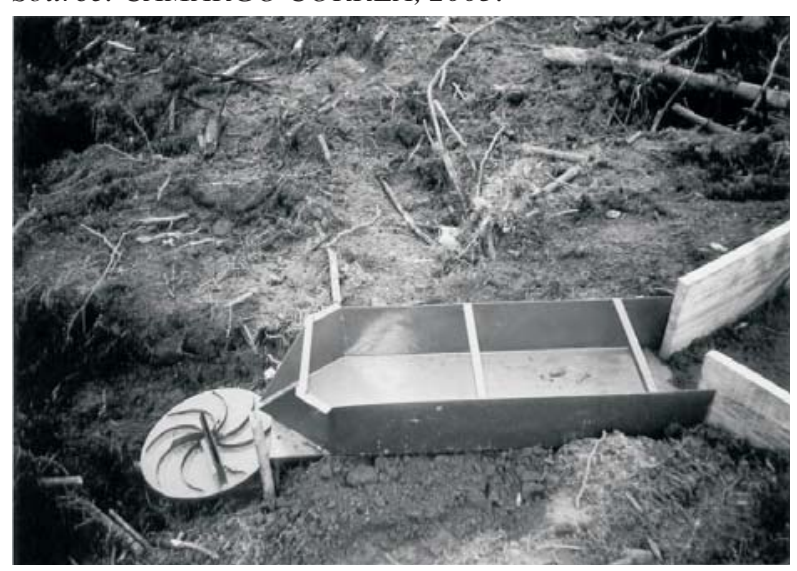

Figura 2 - Detalhes da calha coletora de enxurrada Cochocton, na área de contribuição da estrada com conservação.

Figure 2-Details of Cochocton Runoff Samplers, in contribution area at road without conservation.

no Laboratório de Fertilidade e Análise de Textura, através do método da pipeta, no Laboratório de Física, ambos pertencentes ao Departamento de Solos e Engenharia Agrícola da Universidade Federal do Paraná (UFPR), que segue a metodologia adotada pela EMBRAPA(1997).

As propriedades físicas e químicas das amostras de água coletadas nos baldes foram submetidas à metodologia proposta por Cogo (1978) e as análises das águas, efetuadas no Laboratório de Pesquisas Hidrogeológicas da UFPR, através dos seguintes métodos de análise instrumental: espectrometria de absorção atômica, espectrometria de emissão e fotocolorimetria.

A rugosidade do solo nos trechos de estrada foi determinada através de perfilometria, utilizando-se perfilômetro com barras corrediças. Foram amostrados quatro pontos nos trechos de estrada avaliados, e a tomada desses dados se deu no momento da implantação e final do projeto. A média das diferenças entre a primeira e a última amostragem, considerando-se os quatro pontos amostrados, representa as rugosidades inicial e final dos trechos amostrados.

\subsection{Descrição dos tratamentos}

Os trechos de estrada avaliados estão inseridos em estradas secundárias e divisoras, ou aceiros. Em cada tratamento foi demarcada uma área de amostragem de $1 / 2$ ha, correspondendo às áreas de contribuição adjacentes aos trechos de estradas avaliados. Essas amostragens foram distribuídas nas duas UMFs avaliadas, no Município de Itaiópolis, apresentando as seguintes características:

a) Estradas (E): trechos de estrada com conservação (E CC), com barreiras de contenção da enxurrada associadas às valas de retenção de água, equidistantes em aproximadamente $50 \mathrm{~m}$, que representam as medidas de conservação adotadas pela empresa. As parcelas eram compostas por três barreiras de contenção de enxurrada, sendo uma em cada extremidade e uma central, todas associadas à vala de retenção de água. Os outros tratamentos contemplaram: trecho de estrada sem conservação (E SC), representado por trechos de estradas que não apresentaram medidas de conservação e trechos de estrada do povoamento (E POV), correspondendo a trechos de aceiros ou divisores.

As dimensões das parcelas foram de $100 \mathrm{~m}$ de comprimento de estrada com largura média de $6 \mathrm{~m}$, sendo delimitadas por linhas de drenagem nas laterais das estradas e por barreiras de contenção nas extremidades. Essas parcelas foram protegidas por lonas pretas nas laterais, a fim de evitar a deposição de sedimentos provenientes das respectivas áreas de contribuição, assim como as barreiras de contenção de enxurrada, evitando-se o acréscimo de sedimentos oriundos de outros segmentos da estrada. Na porção mais baixa da parcela, seguindo a linha de drenagem da estrada, foram instaladas as calhas coletoras de solo.

Áreas de Contribuição (C): representam áreas adjacentes às estradas, demarcadas na porção mais alta da paisagem e possuem inclinação direcionada para as estradas equivalentes, com dimensões de $50 \times 100$ m (1/2 ha). Essas áreas foram delimitadas por linhas de drenagem, e na porção mais baixa da paisagem foram instaladas as calhas coletoras de solo. Esses tratamentos contemplaram novos plantios, que haviam passado por preparo convencional do solo utilizado pela empresa, consistindo em enleiramento de resíduos e preparo do solo com subsolador morro abaixo. A área de contribuição do povoamento (C POV), representado pela área adjacente ao trecho de estrada no povoamento E POV, foi demarcada dentro de um povoamento de Pinus taeda com idades de 8 anos.

Os resultados de perdas de sedimentos por processos erosivos, obtidos durante o monitoramento, foram submetidos à análise estatística de Regressão Linear através do programa computacional STATISTICA e 
Tabela 1 - Declividade e legenda dos tratamentos avaliados nas unidades de manejo florestal de Itaiópolis, SC. Table 1 - Slope and treatment legend evaluated in Forestal Management Units (FMUs) in Itaiópolis, SC.

\begin{tabular}{lcc}
\hline Tratamento & \multicolumn{2}{c}{ Município Itaiópolis } \\
\cline { 2 - 3 } & Legenda & $\begin{array}{c}\text { Decliv. } \\
(\%)\end{array}$ \\
\hline Estrada Com Conservação & ITA/E/CC & 12 \\
Estrada Sem Conservação & ITA/E/SC & 13 \\
Estrada Povoamento & ITA/E/POV & 15 \\
Contribuição Com Conservação & ITA/C/CC & 11 \\
Contribuição Sem Conservação & ITA/C/SC & 12 \\
Contribuição Povoamento & ITA/C/POV & 16 \\
\hline
\end{tabular}

Fonte: CAMARGO CORRÊA, 2005.

Source: CAMARGO CORREAA, 2005.

os resultados de perdas totais, confrontados com os estimados através da RUSLE e submetidos à análise estatística através do Teste t, por médias pareadas usando o programa Excel.

Na Tabela 1 são apresentadas a legenda dos tratamentos avaliados e a respectiva declividade.

\subsection{Estimativas de perdas de solo através da RUSLE}

As estimativas de perda de solo foram determinadas através da Revised Universal Soil Loss Equation (RUSLE), que é definida pela equação 1:

$$
A=R \cdot K \cdot L \cdot S \cdot C \cdot P
$$

em que:

A = perda de solo calculada por unidade de área, em tha-1 ano $^{-1}$;

$\mathrm{R}=$ fator erosividade da chuva, em $\mathrm{MJ} \mathrm{mm} \mathrm{ha}^{-1}$ $\mathrm{h}^{-1} \mathrm{ano}^{-1}$;

$\mathrm{K}=$ fator erodibilidade do solo, em $\mathrm{th} \mathrm{MJ}^{-1} \mathrm{~mm}^{-1}$;

$\mathrm{L}=$ fator comprimento de rampa, baseado nos valores em m, da rampa;

$\mathrm{S}=$ fator declividade, baseado nos valores em \% da declividade;

$\mathrm{C}=$ fator uso e manejo, relação entre perdas de solo de terreno cultivado em dadas condições e perdas correspondentes a um terreno mantido continuamente descoberto, ou seja, nas mesmas condições em que o fator $\mathrm{K}$ foi avaliado, adimensional; e
$\mathrm{P}$ = fator prática conservacionista, relação entre as perdas de solo de um terreno cultivado com determinada prática e as perdas quando se planta morro abaixo, adimensional.

\section{RESULTADOS E DISCUSSÃO}

\subsection{Obtenção dos fatores da RUSLE}

As perdas reais de solo provenientes dos trechos de estrada e respectivas áreas de contribuição foram equiparadas com os resultados obtidos através da Equação Universal de Perda de Solo Revisada (RUSLE), cuja composição dos fatores compreende o que se segue.

O fator $\mathbf{R}$ foi determinado em função de histórico diário de precipitação, com informações de intensidade de chuvas, decorrentes do período de março de 2003 a junho de 2004. $\mathrm{O} \mathrm{EI}_{30}$ foi estimado através da equação 2, proposta por Wischmeier e Smith (1959).

$$
E=0,119+0,0873 \log I
$$

em que:

$\mathrm{E}=$ energia cinética por $\mathrm{mm}$ de chuva ( $\mathrm{MJ}$ $\left.\mathrm{ha}^{-1} \cdot \mathrm{mm}^{-1}\right)$; e

$\mathrm{I}=$ intensidade de chuva em $\mathrm{mm} \mathrm{h}^{-1}$.

A chuva acumulada no período de avaliação correspondeu a 1.495,6 mm e resultou numa erosividade de a 9.061,8 MJ.mm ha-1 $\cdot \mathrm{h}^{-1}$.

O fator $\mathbf{K}$ foi calculado com base na equação 3, proposta por Dissmeyer e Foster (1980).

$K=2,1 \mathrm{M}^{1,14} \cdot\left(10^{-6}\right) \cdot(12-\mathrm{a})+0,0325 \cdot(\mathrm{b}-2)+0,025(\mathrm{c}-3)$

em que:

$$
\begin{aligned}
& \mathrm{K}=\text { erodibilidade do solo }\left(\mathrm{t} \cdot \mathrm{h} \mathrm{Mj}^{-1} \cdot \mathrm{mm}^{-1}\right) \\
& \mathrm{M}=(\% \text { silte }+ \text { areia fina }) \cdot(100-\% \mathrm{C}) \\
& \mathrm{a}=\% \mathrm{C} ; \\
& \mathrm{b}=\text { estrutura; } \\
& \mathrm{c}=\text { classe de permeabilidade; }
\end{aligned}
$$

Revista Árvore, Viçosa-MG, v.34, n.4, p.587-595, 2010 
1 = muito fina granular;

2 = fina granular;

3 = média a grossa granular;

4 = blocos, laminar ou maciça;

6 = muito lenta;

5 = lenta;

4 = lenta para moderada;

3 = moderada;

2 = moderada para rápida; e

1 = rápida.

A erodibilidade do solo encontrada nessas UMFs variou entre 0,027 e 0,036 t.h $\mathrm{MJ}^{-1}$. $\mathrm{mm}^{-1}$ em cambissolos e de 0,025 a 0,038 a t.h $\mathrm{MJ}^{-1}$. $\mathrm{mm}^{-1}$ nos Argissolos VermelhoAmarelos.

Para cálculo dos fatores $\mathbf{L}$ e $\mathbf{S}$ foi utilizada a equação 4, proposta por Bertoni e Lombardi Neto (1999), cujos resultados se encontram na Tabela 2.

$$
\mathrm{LS}=0,00984 \cdot \mathrm{C}^{0,63} \cdot \mathrm{D}^{1,18}
$$

em que:

$$
\mathrm{C}=\text { comprimento da rampa }(\mathrm{m}) ; \mathrm{e}
$$

$\mathrm{D}=$ declividade da rampa (\%).

Garcia et al. (2003), avaliando as perdas de solo pelo modelo WEPP, evidenciaram que o efeito do comprimento de rampa (subfator $\mathrm{C}$ ) foi significativo no volume de enxurrada proveniente de estradas, enquanto a declividade (subfator D) não apresentou diferença significativa nos trechos de estradas avaliados. No entanto, quando se compara volume de solo carreado, a relação é inversa para esses subfatores.

O fator $\mathbf{C}$ foi determinado através da equação 5, que representa a soma dos seguintes subfatores:

$\mathrm{C}=\mathrm{CC} . \mathrm{BS} . \mathrm{SR} . \mathrm{SC} . \mathrm{RB} . \mathrm{DE} . \mathrm{CT}$
E a composição dos subfatores foi definida da seguinte forma:

- Cobertura de Dossel ou Solo Descoberto (CC): nesse subfator ficou estipulado o valor de 1 para todos os tratamentos, considerando-se que não apresentam cobertura de dossel nas estradas, e as respectivas áreas de contribuição foram submetidas a corte raso. Nas áreas adjacentes ao trecho de estrada do povoamento, onde havia cobertura de dossel, não foram constatadas perdas de solo durante o período.

- Cobertura da Superfície ou Cobertura por Resíduo (BS): os valores desse subfator foram estipulados através de Dissmeyer e Foster (1980), sendo considerado 0,099 para estradas e 0,055 para as áreas de contribuição avaliadas nessas UMFs, que apresentaram cerca de 80\% da área com solo descoberto.

- Rugosidade Superficial do Solo (SR): neste subfator, utilizou-se a equação 6, proposta por Renard et al. (2000).

$$
S R=\exp ^{[-0,66(R u-0,24)]}
$$

Os valores de rugosidade foram obtidos através de perfilometria, e os resultados estão apresentados na Tabela 2.

- Reconsolidação do Solo (SC): este subfator foi determinado através de Dissmeyere Foster (1980), e os valores estipulados para os trechos de estrada avaliados foram de 0,483 e de 0,245 nas áreas de contribuição dessas UMFs.

Agregação Residual do Uso Anterior (RB): este subfator foi proposto através de Dissmeyer Foster (1980), e os valores estabelecidos para esse subfator variaram entre 0,8 nos trechos de estrada e 0,6 nas respectivas áreas de contribuição.

- Efeito de Degraus (DE): na Tabela 2 estão os valores encontrados para esse subfator, de acordo com Dissmeyer Foster (1980).

Os valores calculados para o fator $\mathrm{C}$ encontram-se juntos com os subfatores Rugosidade Superficial do Solo (SR) e Efeitos de Degraus (DE), na Tabela 2.

O fator $\mathbf{P}$ representa o efeito da prática conservacionista; nas áreas de contribuição, o preparo de solo foi feito morro abaixo, e o valor estipulado 
Tabela 2 - Valores calculados dos subfatores rugosidade de superfície (SR) e efeito de degraus (DE) e dos fatores C e LS, utilizados nas UMFs de Itaiópolis, SC.

Table 2-Subfactors calculated values from superficial roughness and degrees effect and factors $C$ and $L S$, utilized at Itaiópolis/SC FMUs.

\begin{tabular}{lcccc}
\hline Tratamento & SR & DE & Fator C & Fator LS \\
\hline ITA E CC & 0,314 & 0,71 & 0,01 & 3,69 \\
ITA E SC & 0,515 & 0,56 & 0,01 & 3,36 \\
ITA E POV & 0,209 & 0,84 & 0,01 & 4,37 \\
ITA C CC & 0,651 & 0,27 & 0,01 & 2,17 \\
ITA C SC & 0,509 & 0,27 & 0,01 & 1,96 \\
ITA C POV & 0,089 & - & - & 3,05 \\
\hline
\end{tabular}

Fonte: CAMARGO CORRÊA, 2005.

Source: CAMARGO CORREA, 2005.

para esse fator foi 1 nessas áreas. Já nos trechos de estrada avaliados a definição desse fator se deu em função das perdas de solo por tratamento e das perdas totais dos tratamentos em estradas. Dessa forma, foram obtidos os seguintes valores para esse fator, 0,4 nos tratamentos de estrada com conservação, 0,5 nos trechos de estrada sem conservação e 0,1 nos trechos de estradas no povoamento nas duas regiões amostradas.

\subsection{Comparativo entre os valores estimados através da RUSLE $e$ as perdas reais de solo no período}

A erosividade da chuva apresentou comportamento diferenciado nos tratamentos avaliados. Nos trechos de estradas ocorreram 25 eventos de chuva que provocaram perdas de solo, enquanto nas respectivas áreas de contribuição foram constatados 18 eventos.

A combinação de fatores estimados de perdas de solo através da RUSLE e os valores reais observados nos trechos de estrada estão expressos em toneladas por hectare $\left(\mathrm{t} \mathrm{km}^{-1}\right)$, já nas respectivas áreas de contribuição esses valores estão expressos em toneladas por hectare ( $\mathrm{t} \mathrm{ha}^{-1}$ ) nessas UMFs; esses resultados são apresentados na Tabela 3.

As estimativas propostas pela RUSLE apresentaram baixa variação entre os tratamentos de estrada avaliados; quando analisados separadamente, os tratamentos de estrada apresentaram maior proximidade, enquanto nas áreas de contribuição os valores foram superestimados em todos os tratamentos. No entanto, a RUSLE representou boa oportunidade de uso para quantificar as perdas de solo nas áreas avaliadas.
Tabela 3 - Estimativa de perda de solo através da RUSLE e as perdas reais de solo amostradas nas UMFs de Itaiópolis, SC.

Table 3 - Soil losses estimative through RUSLE and real soil losses evaluated in Itaiópolis FMUs.

\begin{tabular}{lccc}
\hline Tratamentos & \multicolumn{3}{c}{ UMFs / ITAIÓPOLIS } \\
\cline { 2 - 4 } & $\begin{array}{c}\text { Perda } \\
\text { Estimada }\end{array}$ & $\begin{array}{c}\text { Perda Real } \\
\text { Acumulada }\end{array}$ & $\begin{array}{c}\text { Estimativa } \\
(\%)\end{array}$ \\
\hline E/CC & 3,54 & 4,07 & $-13,0$ \\
E/SC & 6,38 & 5,24 & $+21,8$ \\
E/POV & 0,96 & 1,40 & $-31,4$ \\
Sub-totais & 10,88 & 10,71 & $+1,6$ \\
C/CC & 0,76 & 0,18 & $+322,2$ \\
C/SC & 0,49 & 0,32 & $+53,1$ \\
C/POV & - & - & - \\
Sub-totais & 1,25 & 0,50 & $+150,0$ \\
TOTAIS & 12,13 & 11,21 & $+8,2$ \\
\hline
\end{tabular}

Fonte: CAMARGO CORRÊA, 2005.

Source: CAMARGO CORREA, 2005.

Na figura 3 estão dispostas as perdas de solo reais e estimadas, provenientes dos trechos de estrada avaliados ( $\left.\mathrm{t} \mathrm{km}{ }^{-1}\right)$ e áreas de contribuição adjacentes $\left(\mathrm{t} \mathrm{ha}^{-1}\right)$.

Os valores estimados através da RUSLE foram confrontados com os valores reais, obtidos através de mensuração, de análise estatística pelo programa Excel e Teste t, considerando-se duas amostras pareadas, em que foi validada a hipótese alternativa conforme os resultados a seguir:

Fonte: CAMARGO CORRÊA, 2005. Source: CAMARGO CORREAA, 2005.

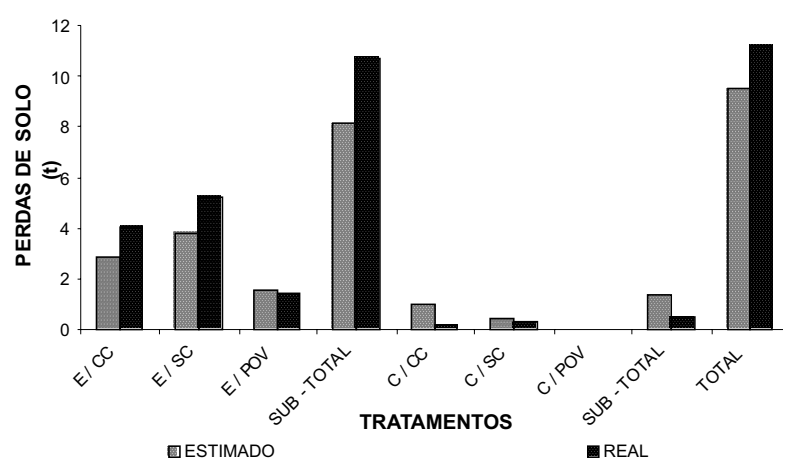

Figura 3-Comparativo entre os valores estimados através da RUSLE e as perdas reais nos tratamentos amostrados nas UMFs de Itaiópolis.

Figure 3-Comparative into estimative values through RUSLE and real soil losses in treatment evaluated in Itaiópolis FMUs.

Revista Árvore, Viçosa-MG, v.34, n.4, p.587-595, 2010 
As perdas totais de solo, que contemplam todos os tratamentos avaliados, apresentaram os seguintes resultados: $\mathrm{N}=6$, Correlação de Pearson $\mathrm{R}=0,9919$, valor $\mathrm{t}=1,08$, t crítico unicaudal $=1,94$ e t crítico bicaudal $=2,45$.

Constatou-se alta correlação entre os valores estimados com os reais e que o valor t se encontra abaixo dos valores críticos propostos pela análise, indicando que as médias não diferem estatisticamente num intervalo de confiança de 95\%.

Quando analisados separadamente os valores de perdas obtidos nas estradas das respectivas áreas de contribuição, o Teste t não identificou diferenças entre as perdas estimadas e as reais, apresentando os seguintes resultados: $N=3$, Correlação de Pearson $R$ $=0,9690$, valor $\mathrm{t}=0,10$, crítico unicaudal $=2,92$ e $\mathrm{t}$ crítico bi-caudal $=4,30$.

Já nas áreas de contribuição, os resultados pelo Teste $t$ apresentaram os seguintes resultados: $\mathrm{N}=3$, Correlação de Pearson $\mathrm{R}=0,6898$, valor $\mathrm{t}=1,45$, $\mathrm{t}$ crítico unicaudal $=2,92$ e t crítico bi-caudal $=4,30$ com dois graus de liberdade.

Essas áreas apresentaram menor correlação, considerando-se 95\% de confiabilidade estatística; no entanto, em todos os testes estatísticos ficou constatada a validade da hipótese alternativa.

\section{CONCLUSÕES}

As estimativas obtidas através da RUSLE apresentaram alta correlação, considerando-se a probabilidade de $95 \%$, e a análise estatística valida a hipótese alternativa que propõe similaridade entre os valores reais e estimados através da RUSLE.

As perdas totais de solo contemplam os três tipos de estradas, e a equação superestimou as perdas reais em $1,6 \%$.

A validação da hipótese proposta indica a viabilidade de utilização da RUSLE para estimativa de perdas de solo em estradas que apresentem condições semelhantes de solo e relevo.

\section{REFERÊNCIAS}

ANTONANGELO, A. Identificação dos riscos de erosão em estradas florestais através de sistemas de informações geográficas. 2004. 100p. Tese (Doutorado em Agronomia) Universidade Eestadual de São Paulo, Botucatu, 2004.
BERTONI, J.; LOMBARDI NETO, F. Conservação do solo. São Paulo: Ícone, 1999. 392p.

BORTOLOZZO, A. R.; SANS L. M. A. Um paralelo entre USLE e suas novas versões. Revista FactuCiência, n. 1, p. 1951 -1958, 2001.

CAMARgo CorrêA, C. M. Perdas de solo e a qualidade da água procedente de estrada de uso florestal no Planalto Catarinense. 2005. 155p. Tese (Doutorado em Ciências Florestais) - Universidade Federal do Paraná, Curitiba, 2005.

CAMARGO CORRÊA, C. M.; ROLOFF, G.; MALINOVSKI, J. R. Parameters of quality of the water originating from forest roads in Brazil. In: ANNUAL CONFERENCE SOIL AND WATER CONSERVATION SOCIETY, 2005, Rochester. Proceedings...

Rochester: Soil and Water Conservation Society, 2005. CD ROM

COGO, N. P. Uma contribuição à metodologia de estudo das perdas de erosão em condições de chuva natural. I. Sugestões gerais, medições dos volumes, amostragem e quantificação de solo e água da enxurrada ( $1^{\text {a }}$ aproximação). In: ENCONTRO NACIONAL DE PESQUISA SOBRE CONSERVAÇÃO DO SOLO, 2., 1978, Passo Fundo. Anais... Passo Fundo: Embrapa/CNPT, 1978. p.75-98.

DISSMEYER, G. E.; FOSTER, G. R. A guide for predicting sheet and rill erosion on forest land. Asheville: Southeastern Forest Experiment Station and Southeastern Area, State \& Private Forestry Atlanta, 1980. (Technical Publication SA-TP-11).

EMPRESA BRASILEIRA DE PESQUISA AGROPECUÁRIA - EMBRAPA. Serviço Nacional de Levantamento de Conservação de Solos. Manual de métodos de análise de solos. Rio de Janeiro, 1997. v. 1.

GARCIA, A. R. et al. . Volume de enxurrada e perda de solo em estradas florestais em condições de chuva natural. Revista Árvore, v. 27, n. 4, p.535-542, 2003. 
GAYOSO, J.; ALARCÓN, D. Manual de implementación de un sistema de gestión ambiental en la empresa forestal. Chile: UACH, INFOR, 1999. 96p.

LOPES, E. S.; MACHADO, C. C.; SOUZA, A. P. Classificação e custos de estradas em florestas plantadas na região sudeste do Brasil. Revista Árvore, v. 26, n. 3,p. 329-338, 2002.

MACHADO, C. C. et. al. Comparação de taxas de erosão em estradas florestais estimadas pelo Modelo Wepp (Water Erosion Prediction Project) modificado em relação a medições experimentais. Revista Árvore, v. 27, n. 3, p. 295-300, 2003.

BRASIL. Ministério das Minas e Energia. Mapa Geológico do Estado de Santa

Catarina. Florianópolis: Secretaria da Ciência e Tecnologia, Minas e Energia. Coordenadoria dos Recursos Minerais, 1986

PARSONS, D. A. Coshocton - Type runoff samplers. Laboratory investigations. Washington: United States Departament of Agriculture, 1954. 16 p. (Soil Conservation Service, 25)
PINTO, L. M. Relatório sumários de avaliação do sistema d manejo florestal da RIGESA Celulose Papel e Embalagens Ltda nos estados de Santa Catarina e Paraná: Norma de Referencia: NBR 14.789:2001. 2005. 52 p.

RENARD, K. G. et al. (Coords.). Predicting soil erosion by water: a guide to conservations planning with the revised soil loss equation (RUSLE). Washington: Departament of Agriculture, 1997. 404 p. (Agric. Handbook, n. 703).

RIGESA, 2004. Levantamento de solos da empresa. (Documento Interno)

WISCHMEIER, W. H. A rainfall erosion index for a universal soil loss equation. Soil Science American Proceddings, v. 23, n. 2, p. 246-249, 1959.

WISCHMEIER, W. H.; SMITH, D. D. Predicting rainfall erosion losses; a guide to conservaion planting. Washington, USDA 1978. 58 p. (Agriculture Handbook, 537) 